\title{
Creating More Than Just a Snapshot: Photography for Planning and Design
}

\author{
Michael Heater \\ Photographer; MCRP student.
}

\author{
Brian Harrington \\ Architect; MCRP student.
}

For the planning and design professions, portraying a building or a place is not just about taking a quick snapshot. It requires deliberate thinking and basic compositional skills for an effective result. MCRP students

Michael Heater and Brian Harrington discuss this important subject and provide examples and techniques.

$P^{n}$ hotography in the urban planning profession is an incredible asset to visual communication. It provides an opportunity to remember, wonder, inspire, and create. The role of photography should not be undervalued. Besides presenting a visually appealing image to the public and decision makers, a photograph is able to explore the relationship between identity and place.

It is important for a planner to recognize that there are many different sides of the city, both good and bad. Documenting these aspects not only serves as a historical record but it shows the changes in an area over time.

There are some simple compositional techniques you can use to make a snapshot into a stunning image. It is important to understand some basic elements of photography that can be useful in a planning career. Consider a photograph a way of documenting and archiving urban memory. Below are city images from the authors, as well as information on simple, compositional techniques that you can use as a planning professional.

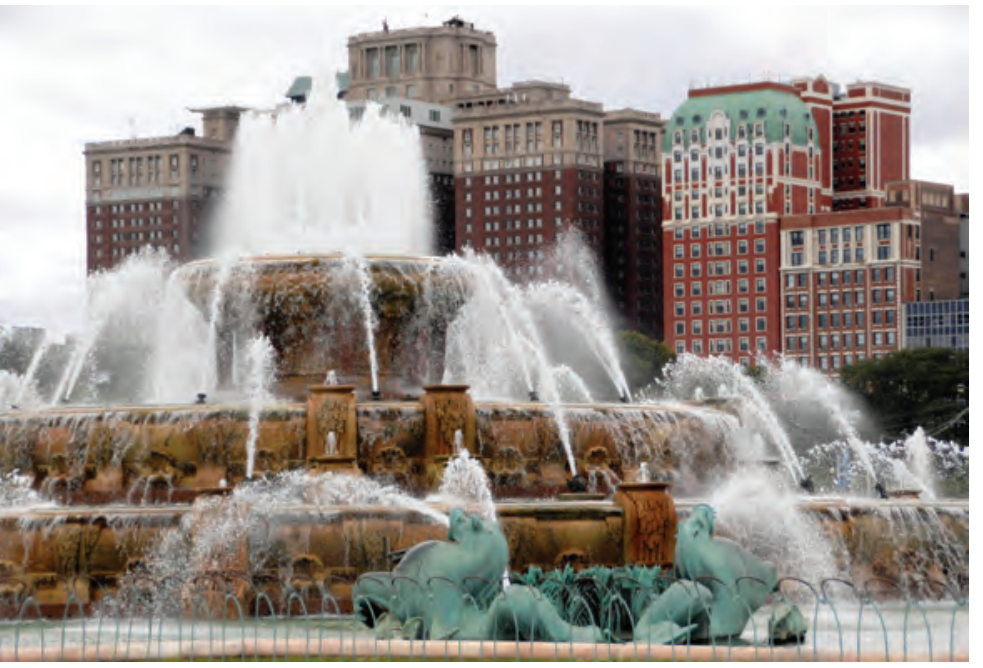

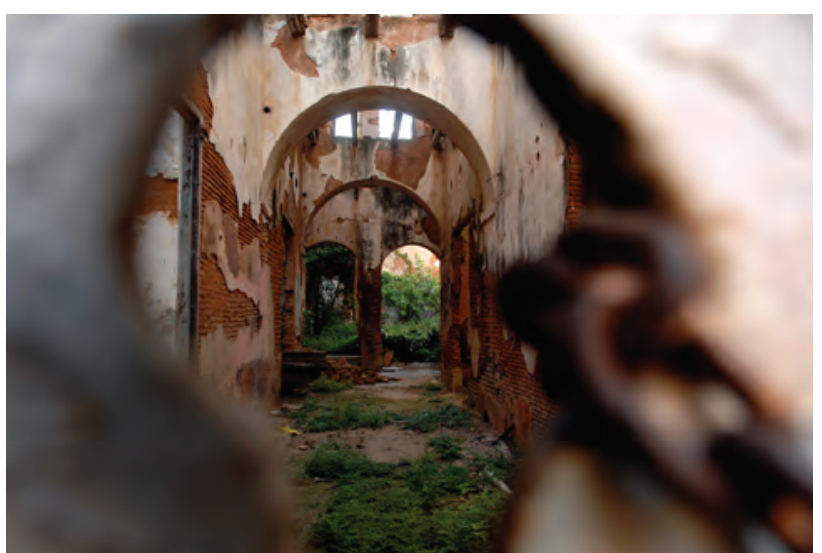

Image 1: This image shows one of the many abandoned structures in Old San Juan, Puerto Rico. Although the roof has collapsed and nature has slowly taking over, there is an element of beauty in its decay. This image shows an example of framing. This is a simple compositional technique a photographic-minded planner can use in the field to frame the center of interest with objects in the foreground. This adds a feeling of depth, creating an overall more appealing photo. (photo by M. Heater)

Image 2: The Clarence F. Buckingham Memorial Fountain in Chicago's Grant Park. It is a magnificent structure. You can really get some stunning images when you fill the frame with the subject. Often, people will shoot a subject that is so distant you can barely make out what it is. You can either fill the frame by using a zoom lens if you have it, or simply move closer to the subject. Once again, this is not always a rule. In many cases, you may find it more appropriate to shoot at a wide angle leaving large empty spaces in your frame. The composition of the fountain in the left corner of the image serves as a pathway for the viewer's eye to travel diagonally until they reach the city skyline in the background. In the planning profession, creating a layered image like this helps convey a more complete story and highlight the complexity of a city. (photo by M. Heater) 
Image 4: The image here was shot during a rainy day in Old San Juan, Puerto Rico. When taking photos, don't be afraid to add people in the shot. Photographing people in the urban environment adds complexity to the scene and tells a story. Also, when the forecast calls for rain, don't hesitate to bring your camera along. Weather adds a nice element to the photo. There is no rule that says you need to shoot on bright, sunny days. (photo by M. Heater)

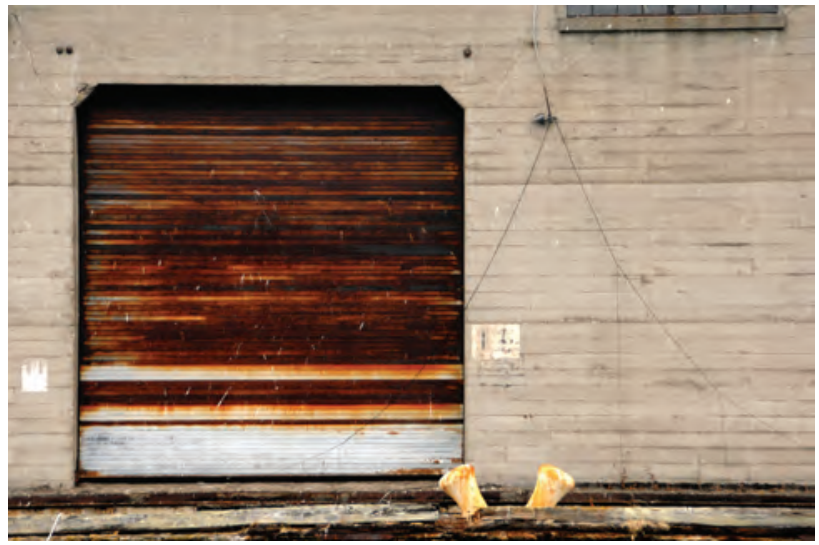

Image 5: This image was taken in the McDougall-Hunt neighborhood northeast of downtown Detroit. News stories and headlines, particularly in the planning field, paint a picture of mass vacancy in Detroit. The composition of this image is meant to counter that expectation with a simple minor detail. Let your photos tell a story. As shown, the chairs' intentional lean against the table show that lots are not vacant, and suggests people could be back anytime soon. (photo by B. Harrington)

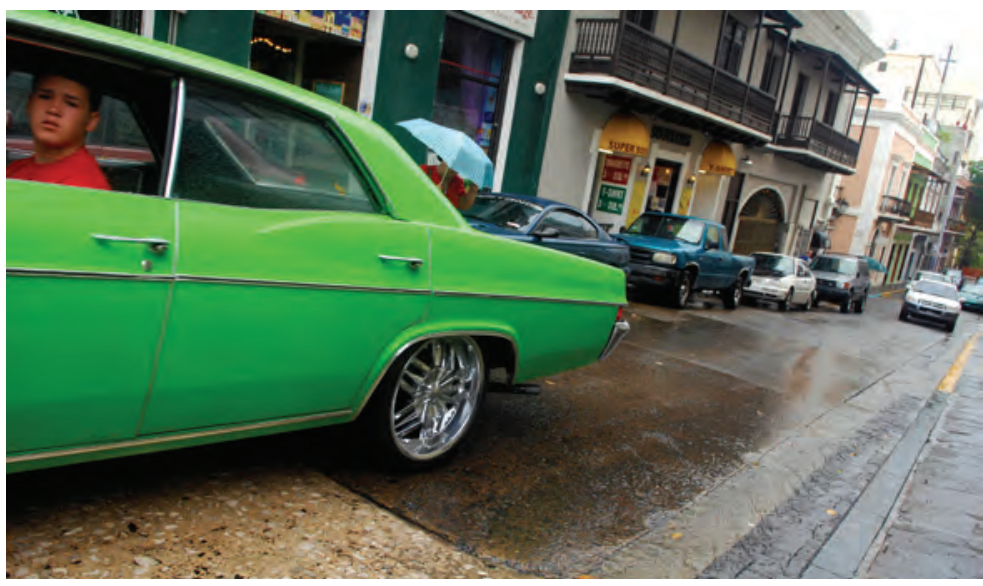

Image 4: The rusted loading door was shot in San Francisco at Fisherman's Wharf. Color adds so much interest to a photo. The urban environment is filled with color! Try looking for lots of color and contrast in your photos. One of the most important and most often used compositional guidelines in photography is known as the rule of thirds. Think of the rule of thirds as basically placing a grid with two vertical and two horizontal lines on top of the image. A photographer can add lots of visual interest and balance to an image by placing certain elements along these lines or at intersecting points. Some cameras even have a feature that superimposes this grid onto the LCD screen, helping the photographer compose the image. (photo by $M$. Heater)

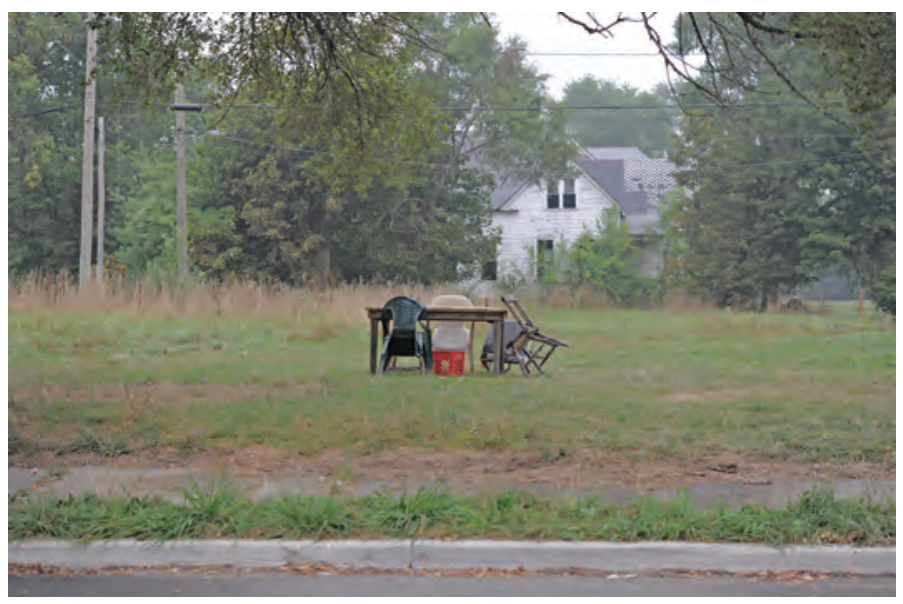

Image 6: As planners, we are interested in understanding and mapping the land uses of communities. It's always fascinating to see the patterns generated by agricultural land, residential development and downtown grids. This image of agricultural land was taken from a single engine four-seat plane from 6,000 feet, near the "thumb" of Michigan, about 100 miles north of Detroit. You can capture of a variety of scales from the seat of any airplane. The next time you take a plane ride, don't forget to bring your camera. (photo by B. Harrington) 
Image 7: Taken in the "Theater District" near Grand Circus Park and Detroit's professional sports stadiums, the image shows one of the more well known and recently redeveloped parts of the city. Viewing the free-standing, remnant facade allows one to reimagine a historical building's view of the downtown's skyline, as suggested by the sign at the bottom right. As shown here, desaturation of a photograph into black and white can be used to obscure a sense of time in your images. (photo by $B$. Harrington)
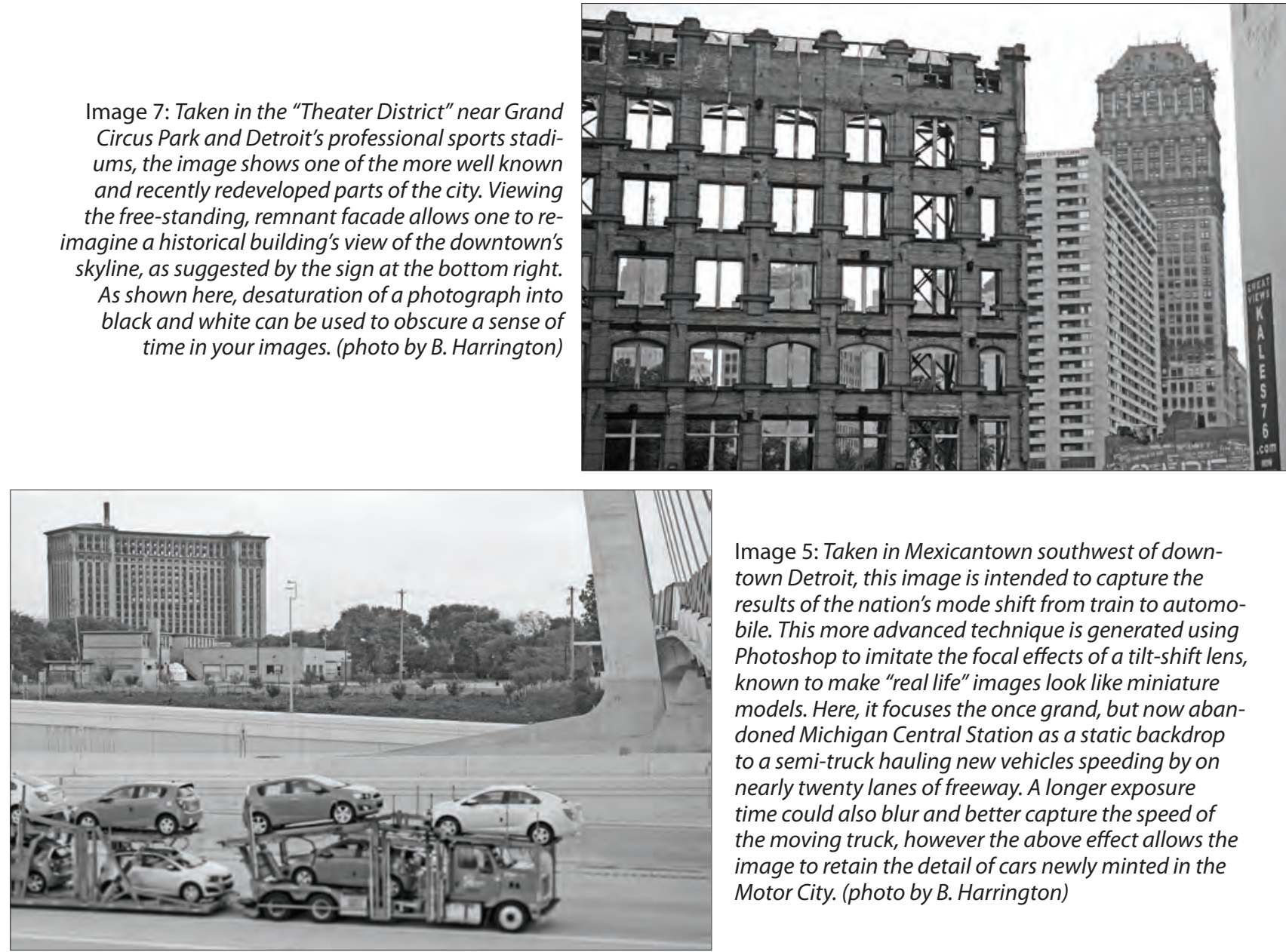

Image 5: Taken in Mexicantown southwest of downtown Detroit, this image is intended to capture the results of the nation's mode shift from train to automobile. This more advanced technique is generated using Photoshop to imitate the focal effects of a tilt-shift lens, known to make "real life" images look like miniature models. Here, it focuses the once grand, but now abandoned Michigan Central Station as a static backdrop to a semi-truck hauling new vehicles speeding by on nearly twenty lanes of freeway. A longer exposure time could also blur and better capture the speed of the moving truck, however the above effect allows the image to retain the detail of cars newly minted in the Motor City. (photo by B. Harrington)

Basic Photo Composition Techniques - The following before and after images may help you to guide your practice. Ansel Adams, landscape photographer of the American West once said, "There are no rules for good photographs, there are only good photographs." It is true that there are no fixed rules in photography, but there is a set of compositional guidelines that will enhance the impact of your photos. All of the photos below were taken on the Cal Poly campus. You'll find the guidelines outlined in the captions can elevate a snapshot into a more compelling image.

Bishops Peak - Before/After: Avoid distraction in your photography by changing the angle of the photo. Consider moving to a different spot or zooming in. Cars and buildings are distracting to the viewer because they take your eye away from the subject. Try and focus on the subject itself. A busy background can distract a viewer's attention and detract from the subject. Frame the center of interest with objects in the foreground. This helps provide depth in a photo as shown in this image of Bishop's Peak. (photos by M. Heater)
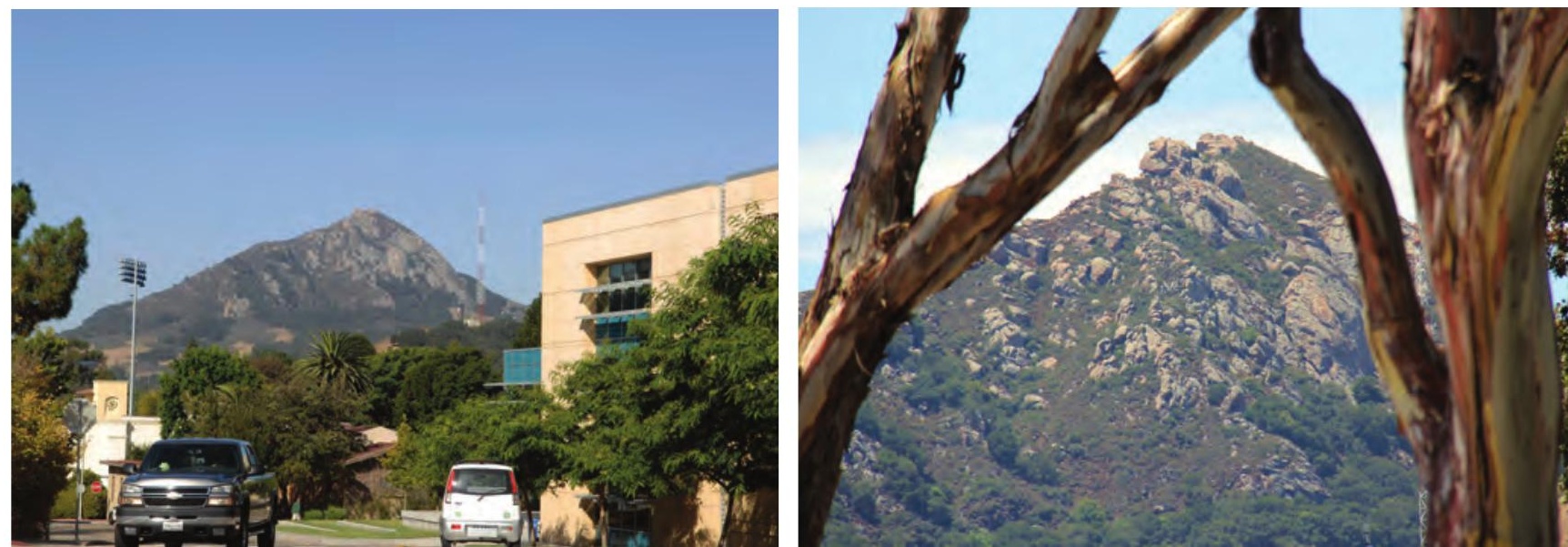

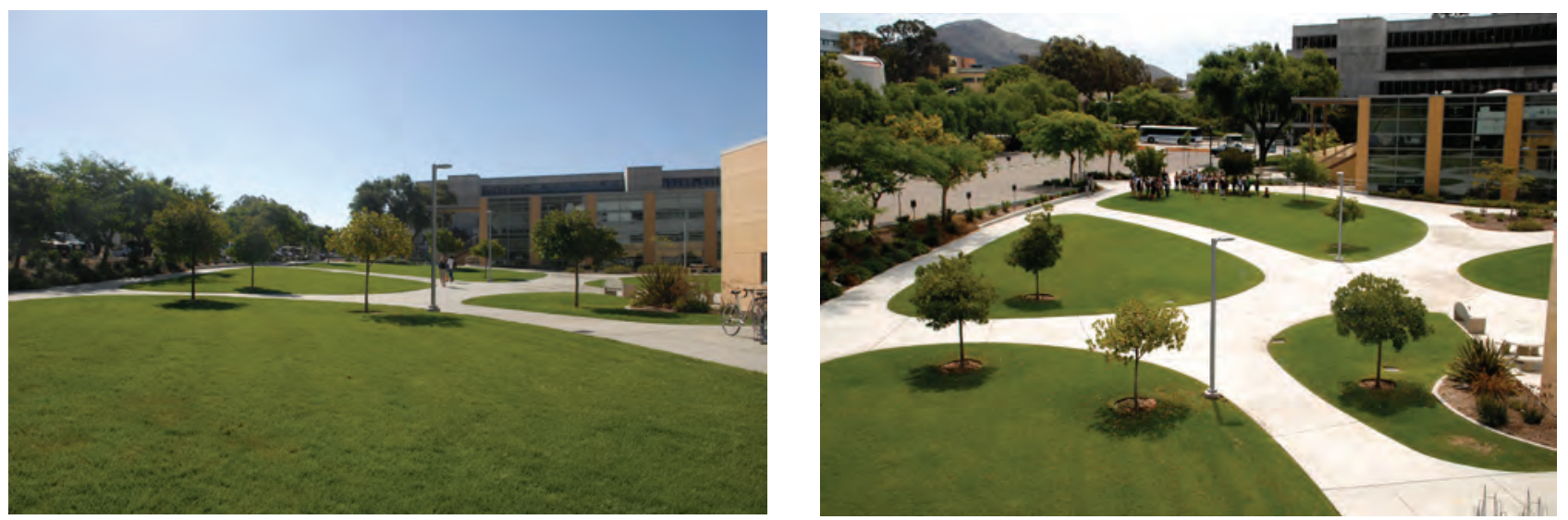

Cal Poly's Bonderson Center - Before/After: One of the easiest ways to compose an interesting image is to change your viewpoint. Most people shoot from eye level, creating a picture that is often flat and dull. Try shooting low at the ground level or climbing up a set of stair to get a higher vantage point. (photos by M. Heater)
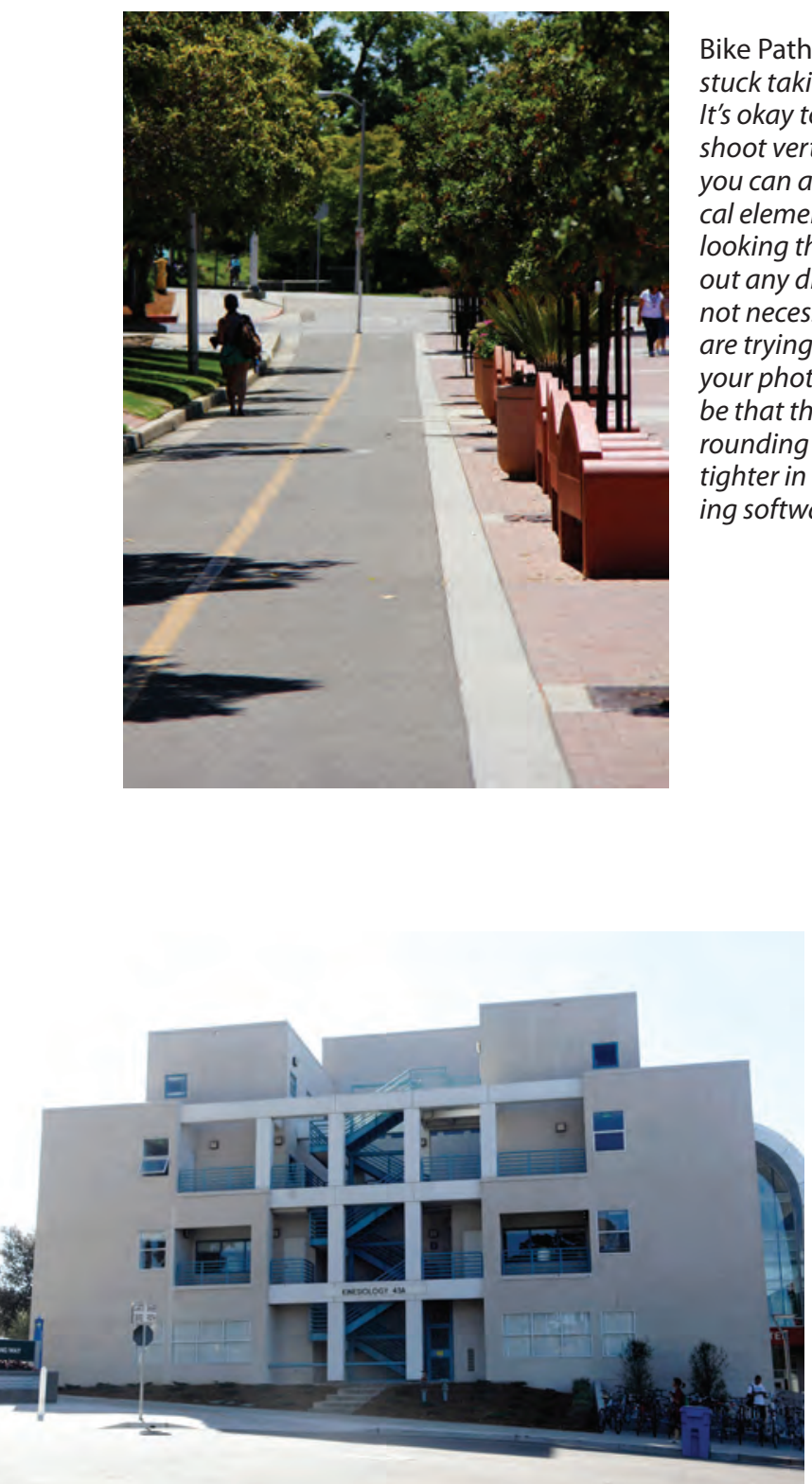

Bike Path - Before/After: Don't get stuck taking horizontal pictures. It's okay to turn the camera and shoot vertical. By shooting vertical, you can accentuate the vertical elements in the photo. When looking through the camera, take out any distracting parts that are not necessary. Focus on what you are trying to convey. If you notice your photos lack impact, it might be that the subject is lost in the surrounding clutter. Crop the image tighter in camera or by using editing software. (photos by M. Heater)

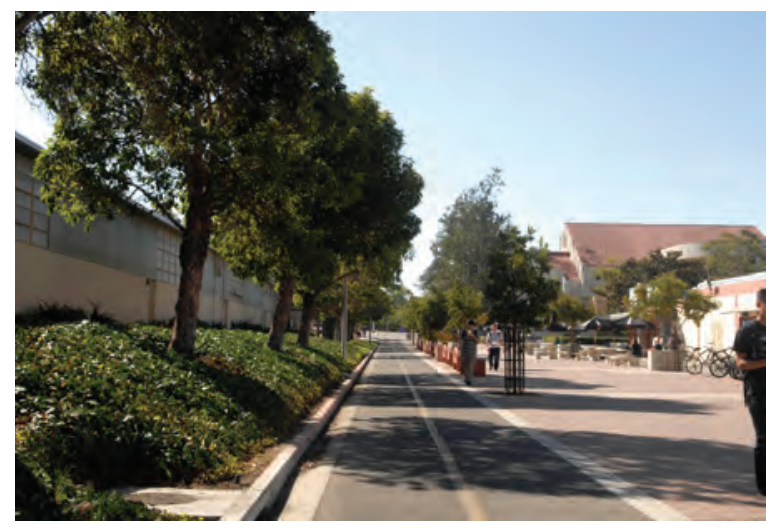

Cal Poly's Kinesiology Building - Before/After: When you start taking photographs you begin to notice symmetry and pattern that surround us. These tend to lend themselves to striking compositions. Taking pictures of buildings is difficult. They are static and often uninteresting. A few techniques that can transform a picture into a more compelling image; framing the subject, adding a human element, and silhouetting. (photos by M. Heater)

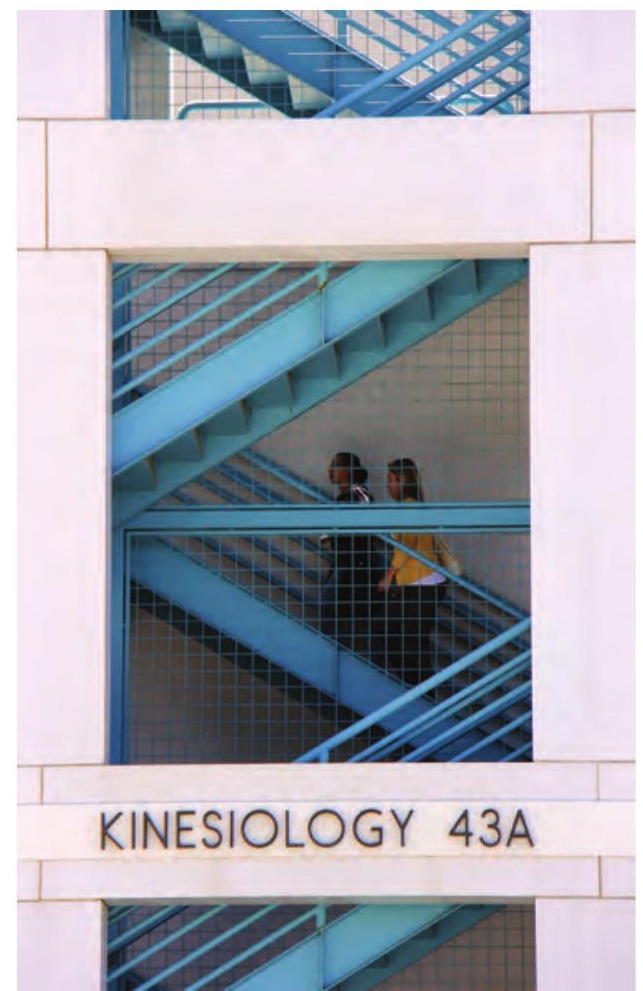

